\title{
Autosomal recessive malignant osteopetrosis
}

INSERM

\section{Source}

INSERM. (1999). Orphanet: an online rare disease and orphan drug data base. Autosomal recessive malignant osteopetrosis. ORPHA:667

Infantile malignant osteopetrosis is a rare congenital disorder of bone resorption characterised by generalised skeletal densification. 